\title{
Effectiveness of job rotation for preventing work-related musculoskeletal diseases: a cluster randomised controlled trial
}

\author{
Maria Luiza Caires Comper, ${ }^{1,2}$ Jack Tigh Dennerlein, ${ }^{3,4}$ Gabriela dos \\ Santos Evangelista, ${ }^{2}$ Patricia Rodrigues da Silva, ${ }^{5}$ Rosimeire Simprini Padula ${ }^{1,5}$
}

\begin{abstract}
'Masters and Doctoral Programs in Physical Therapy, Universidade Cidade de São Paulo, São Paulo, Brazil ${ }^{2}$ Department of Physical Therapy, União Metropolitana de Ensino e Cultura, Itabuna, Brazil

${ }^{3}$ Department of Environmental Health, Harvard T.H. Chan School of Public Health, Boston, Massachusetts, USA ${ }^{4}$ Department of Physical Therapy, Movement, and Rehabilitation Sciences, Bouvé College of Health Sciences, Northeastern University, Boston, Massachusetts, USA

${ }^{5}$ Department of Physical Therapy, Universidade Cidade de São Paulo, São Paulo, Brazil
\end{abstract}

Correspondence to Dr Maria Luiza Caires Comper, Masters and Doctoral Programs in Physical Therapy, Universidade Cidade de São Paulo, Rua Cesário Galeno 475, São Paulo 03071-000, Brazil; marialuizacaires21@hotmail. com

Received 7 September 2016 Revised 26 December 2016 Accepted 3 January 2017 Published Online First 1 March 2017

\section{Linked}

- http://dx.doi.org/10.1136/ oemed-2017-104301

\section{CrossMark}

To cite: Comper MLC, Dennerlein JT, dos Santos Evangelista G, et al. Occup Environ Med 2017;74:545-552.

\section{ABSTRACT}

Objective Job rotation is an organisational strategy widely used on assembly lines in manufacturing industries to mitigate workers' exposure so as to prevent musculoskeletal disorders. This study aimed to evaluate the effectiveness of job rotation for reducing working hours lost due to sick leave resulting from musculoskeletal diseases.

Methods The design consisted of a 1-year cluster randomised controlled trial with a blinded assessor. Production sectors of the textile industry were randomised to intervention and control groups. Both groups received ergonomic training. The intervention group performed a job rotation programme. The primary outcome measure was number of working hours lost due to sick leave as a result of musculoskeletal disease (ICD-

10). The secondary outcome measures were musculoskeletal symptoms (Yes/No), risk factors for musculoskeletal diseases (0-10), psychosocial factors and fatigue (0-100), general health (0-100), and productivity (0-10). All secondary outcomes were measured at baseline and 12-month follow-up.

Results At the 12-month follow-up, both groups showed an increase in the number of working hours lost due to sick leave for musculoskeletal disease. There was no significant difference between the job rotation intervention group (mean deviation -5.6 hours, $95 \% \mathrm{Cl}$ -25.0 to 13.8 ) at the 12-month follow-up and the control group. There were no significant differences between groups for the secondary outcomes ( $p>0.05$ ). Conclusions The job rotation programme was not effective in reducing the number of working hours lost due to sick leave, decreasing the prevalence of musculoskeletal symptoms, or improving perception of musculoskeletal pain and workplace risk factors, psychosocial risk factors and productivity.

Trial registration number NCT01979731.

\section{INTRODUCTION}

Job rotation is an organisational ergonomic strategy used widely on assembly lines in manufacturing industries. $^{1}$ It is defined as rotation of workers between jobs or tasks with different exposure levels and occupational demands. ${ }^{2}$ Job rotation has been used as an administrative practice to train workers for new jobs so that they can acquire additional abilities at work, increase performance and autonomy, and improve organisational flexibility. ${ }^{3}$ Several studies also recommend job rotation as an effective

\section{What this paper adds}

- This study is the first randomised controlled trial performed to evaluate job rotation effectiveness in preventing and controlling work-related musculoskeletal diseases.

- Job rotation was not more effective for the intervention group compared with the control group in reducing the number of working hours lost due to sick leave for musculoskeletal disease.

- These results challenge the concept that job rotation is a good organisational strategy for preventing and controlling musculoskeletal complaints, particularly in work settings where exposure levels cannot be reduced because of the characteristics of the job or through physical measures.

- We recommend that care should be taken in translating these results to all manufacturing industries. It is necessary to consider the specifics of the job, settings, and organisation preferences and necessities.

intervention for mitigating physical and mental exposure, increasing satisfaction at work, ${ }^{4}$ and reducing monotony and boredom, ${ }^{5}$ thereby preventing musculoskeletal disorders and reducing absenteeism. ${ }^{67}$

Despite the potential benefits of job rotation for reducing exposure and preventing musculoskeletal disorders, as widely propagated among industrial managers and described in the literature, two recent systematic reviews reported weak evidence for job rotation effectiveness and indicated that it increases exposure. $^{8}{ }^{9}$ Only the study of Padula $e t a l^{8}$ focused on the concept of job rotation proposed for manufacturing industries. It demonstrated that few studies have evaluated the benefit of job rotation to musculoskeletal health in industrial environments. In addition, the studies included in that review had poor or fair methodological quality and the majority used a cross-sectional design.

The inappropriate designs used to assess the outcomes related to job rotation effects make it difficult to establish proper parameters for organisation and implementation of a job rotation programme 
(JRP). In the absence of this evidence, the most appropriate approach is to use the systematisation of studies. ${ }^{10}$ To meet these goals, job rotation implementation in a manufacturing industry must include: acceptance and involvement of managers and workers; assessment of the job characteristics (demands, biomechanical exposure levels, autonomy) and the production method; choosing the number of employees per task; and definition of criteria and parameters that will be used to generate a job rotation schedule. ${ }^{1} 1112$ Training all workers according to their competences before implementing job rotation is also important. 8

Therefore, a high-quality methodological study designed to examine all recommendations reported for implementing JRPs should be performed to answer the question: what is the effect of job rotation in preventing musculoskeletal disorders among industrial workers?

The aim of this study was to investigate the effectiveness of job rotation in reducing working hours lost due to sick leave for musculoskeletal diseases among industrial manufacturing workers. The hypothesis was that job rotation could reduce the exposure generated by specific tasks, leading to a decrease in the number of working hours lost due to sick leave resulting from musculoskeletal disease. In addition, it could decrease the prevalence of musculoskeletal symptoms, improve workers' perception of the reduction in risk factors that lead to musculoskeletal diseases, and increase productivity.

\section{METHODS}

Design, setting and participants

This was a prospectively registered (at ClinicalTrials.Gov (NCT01979731), 3 November 2013) cluster randomised controlled trial (RCT) with a blinded assessor. The procedures and consent form were approved by the research ethics committee of Universidade Cidade de São Paulo. The study was conducted at a large Brazilian textile factory with 10 production sectors $(n=1897$ workers). Four production sectors (finishing socks, finishing underwear, sewing socks and sewing underwear) met the eligibility criteria and were included in the study $(n=581)$. The eligibility criteria were that the workers were arranged in a manufacturing cellular and serial layout with jobs or tasks with different biomechanical demands and levels of risk for musculoskeletal disorders. Sewing production sectors were characterised by: prolonged sitting; repetitive movements of the wrists, hands and fingers; and static muscular overload on the spine and shoulders. Finishing production sectors were characterised by: prolonged standing; material-handling tasks; small displacements between workstations; and repetitive movements of the shoulders, wrists and hands. These workers had never performed job rotation.

The detailed methods of the study have been published as a study protocol. ${ }^{13}$ The only change in method, which occurred after the start of the trial, was the follow-up interval for secondary outcomes. The interval of 3 months (baseline, 3, 6, 9, 12 months) was changed to baseline and 12-month follow-up because managers would not allow evaluation of the secondary outcomes every 3 months as described in the research protocol, because of the time spent answering the questionnaires at baseline.

\section{Description of intervention and control groups}

Both workers' groups received ergonomic training, which was carried out by a physiotherapist/ergonomist with 10 years of experience. The training was conducted on a single day over 4 hours and consisted of lectures on physical, organisational, cognitive and psychosocial risk factors (posture demands, movements, furniture, workplace, tools, rest break and micro-break, learning, engagement, responsibility, concentration, environmental factors) and the importance of physical exercise for maintaining health. ${ }^{14}$ The ergonomic training was used as a sham intervention and is considered an educative strategy, which showed insufficient evidence of effectiveness of health training for reducing symptoms, illness and injury when delivered as a standalone intervention. ${ }^{15}$

\section{JRP (intervention group)}

Procedure to create and implement the JRP

The JRP consisted of the following four phases.

Phase 1: overview of tasks (June 2013 - September 2013)

Meetings between the physiotherapist/ergonomist and production managers were organised to explain the study proposal and procedures, as well to define the production sectors that met the eligibility criteria. Managers then explained the general characteristics of each task, production targets, operation process (technical, equipment and tools, autonomy and pace of work) and the level of training required.

Phase 2: ergonomic analysis (October 2013 - November 2013)

Ergonomic analysis for each task was performed by the ergonomist, who visited the workplace to interview workers and conduct a worksite observation. First, he observed the main demand, work posture, movements of each body region (amplitude and frequency) and work cycles. He then collected information on productivity, autonomy, job organisation, job planning, production instructions, skills of workers, materials and equipment used.

The exposure levels were classified using two observational methods: quick exposure check (QEC) ${ }^{16} 17$ and rapid entire body assessment (REBA). ${ }^{18}$ QEC includes 16 questions about posture and movements performed by the spine and upper limbs, as well as other risk factors (amount of weight handled; how long it takes to perform a task; manual force; visual demands; vibration and level of hand force exerted; work pacing; and stress). This score results from combining answers given by the evaluator and the worker. ${ }^{16}{ }^{17}$ REBA assesses biomechanical exposure, mainly body posture, and incorporates variables such as weight and quality of the handle of the handled object. Both methods classify the task as low, moderate, high or very high exposure level. ${ }^{18}$ Task complexity was categorised as easy or difficult on the basis of cognitive demands and learning time. ${ }^{19}$

Phase 3: definition of job rotation schedule (December 2013 January 2014)

All information obtained in the earlier phases was used to define a job rotation schedule proposed to modify occupational exposure.

Job rotation was alternated between exposure levels: low, moderate and high. A job rotation schedule with an interval of 2 hours was adopted. This interval was a consensus between studies 1926 and is compatible with the premise of lactic acid reduction. $^{20}$

The workers were gradually allocated to the tasks incorporated in the job rotation schedule and were coached by their supervisors until they reached an adequate performance. Two months of training was established as the time required for workers to be able to satisfactorily perform these specific tasks. Phase 4: implementation of job rotation (February 2014February 2015)

Finally, implementation of the job rotation schedule occurred in the fourth phase (February 2014-February 2015). One of 
the researchers monitored the fourth phase daily during the first 2 months. Monitoring was accomplished through interviews with workers and supervisors to evaluate whether (1) job rotation was being implemented as proposed by the team, (2) the company's target was being achieved, and (3) problems related to job rotation had occurred.

\section{Sample size calculation}

The study was designed to detect differences between the groups of a $10 \%$ reduction in the number of working hours lost due to sick leave for musculoskeletal disease ( $\mathrm{M}$ code of International Classification of Diseases: ICD-10). ${ }^{21}$ The total working hours lost due to sick leave (ICD-10) in 3 months for all workers in the whole workplace was $\sim 1100$ (on average 360 hours per month and $\sim 81$ hours per week). A statistical power of $80 \%$, an $\alpha$ of $5 \%$, and a possible sample loss of up to $15 \%$ were also considered. Therefore, a total of 232 participants was required.

\section{Randomisation}

Randomisation for clustering was performed at the group level (production sectors). An independent researcher who was not involved in recruitment and assessment used computergenerated randomisation (http://www.randomizer.org) to assign participation to intervention and control groups. All workers were allowed to participate in the study, and those who agreed signed a consent form before entering the study.

\section{Outcome measures}

The unit of randomisation was by cluster, although all outcomes were evaluated and statistically analysed at an individual level.

\section{Primary outcome}

The increase in cost caused by absence due to musculoskeletal disease is a major problem for organisations. ${ }^{22} 23$ This was the reason the primary outcome measure was chosen as absence from work due to sick leave, assessed by the number of working hours lost from musculoskeletal disease. We considered only sick leave certificates classified with the $\mathrm{M}$ code, which includes diseases (signs, symptoms, abnormal findings, symptoms, injuries) of the musculoskeletal system and connective tissue, from ICD-10. ${ }^{21}$ Registration of workers with sick leave certificates was completed daily by the human resources sector and included information on the reasons for the medical certificate and the number of days lost. All information was obtained by electronic report, extracted monthly by a person unaware of the study or group participants. Then, average working hours lost for each individual and per group (intervention and control) every 3 months was calculated for analysis at baseline, 3, 6, 9 and 12 months. These data were collected between February 2014 and March 2015. The baseline data refer to the months of November and December of 2013 and January of 2014.

\section{Secondary outcomes}

The secondary outcome measures evaluated were: musculoskeletal symptoms; workers' perception of risk factors for the occurrence of musculoskeletal pain; fatigue and psychosocial factors; general health; productivity. These outcome measures may indicate the effect of the intervention (job rotation) on workers' exposure to risk factors for musculoskeletal diseases.

The Nordic Musculoskeletal Questionnaire was used to assess musculoskeletal symptoms (pain, tingling and numbness). The workers answered 'yes' or 'no' for prevalence of musculoskeletal symptoms, experienced during the previous 12 months, by areas of the body (neck, shoulders, elbows, hands, upper back, lower back, hips, knees and feet). ${ }^{24}$

The Job Factors Questionnaire was used to assess workers' perceptions as influenced by exposure factors on the occurrence of musculoskeletal diseases, and contained a descriptive list of 15 job risk factors. ${ }^{25} 26$ Each factor was classified on a scale of 0 to 10,0 meaning 'no problem' and 10 'very problematic.' $25 \mathrm{~A}$ total score was obtained by adding the scores of the 15 job risk factors. Higher scores indicated greater risk of developing musculoskeletal diseases.

The Need for Recovery Scale (NFR) is a Likert scale based on 11 questions, each with four answers (never $=0$; sometimes $=1$; often $=2$; and always $=3$ ). ${ }^{27}$ Question 4 was reverse scored. The total scores ranged from 0 to 33 points, which was then converted into a scale ranging from 0 (minimum) to 100 (maximum) points. NFR is based on the effort-recovery model of the working day. Thus, higher NFR scores indicate a greater perception of fatigue by workers and consequently a greater need for recovery. ${ }^{28}$

The WHO Quality of Life Scale (WHOQOL-BREF) is a 26-item, self-reported survey. The first two items assess the general quality of life, and the remaining 24 items were structured into four domains: social, psychological, physical and environmental. Each domain consisted of questions scored on a 5 -point Likert interval scale. ${ }^{28} 29$ Total raw scores for each domain were transformed into scores ranging from 0 to 100 . A higher score indicated a better quality of life. ${ }^{30}$

A single item from the WHO Health and Work Performance Questionnaire was used to measure productivity. ${ }^{31}$ Participants were assigned a score (0-10) for their labour productivity.

Secondary outcomes were measured by a blinded evaluator at baseline and 12-month follow-up. To test the evaluator blinding, his opinion about the type of intervention received by each worker was noted after follow-up.

\section{Monitoring data}

The data monitoring committee consisted of two authors from the study (MLC and RSP) who were not involved with data collection and have no conflict of interest. Randomisation of the participants was performed after the baseline, but randomisation was performed by cluster (production sector). The researcher (MLC) who performed the statistical analysis received the data encoded and was blinded to the participant's allocation to intervention groups. Statistical analysis was conducted on an intention-to-treat basis; participants were analysed in the groups to which they were randomly allocated. If a participant dropped out of treatment, no additional outcomes were collected and the missing data were not replaced.

\section{Statistical analysis}

The Shapiro-Wilk test was used to assess the normality of the data. Descriptive statistics were used in the analysis of characteristics of the participants. The $\chi^{2}$ test was used to evaluate the blinding of the assessor by comparing the randomisation codes and the evaluator. ${ }^{32}$ The difference between the groups and their respective CIs was calculated using linear mixed-effects models, taking into account the units of analysis for each participant (individual differences-repeated measures), by time and group vs time interaction terms. ${ }^{33}$ The within-group difference was calculated using Student's paired t-test for dependent samples. The difference between the groups for nominal data was calculated using McNemar's test. The significance level was $5 \%$. The statistical program SPSS V.23.0 was used for all analyses. 


\section{RESULTS}

Participant flow and loss to follow-up

A total of 10 production sectors ( $n=1897$ workers) were assessed, but only four ( $\mathrm{n}=957$ workers) were included under the eligibility criteria. Of these, 136 workers refused to participate, and 330 were dismissed for business reasons. Therefore, after randomisation, two production sectors $(n=266$ workers) were allocated to the intervention group and two $(n=225)$ to the control group. Figure 1 shows enrolment, intervention allocation, follow-up and data analysis of the production sectors and participants in this trial.

At the 12-month follow-up, 123 workers had been dismissed for business reasons, and 32 workers from the JRP did not finish the intervention because of a decision made by the company's management. The loss therefore to follow-up on the primary and secondary outcome measures was $24.8 \%$ in the

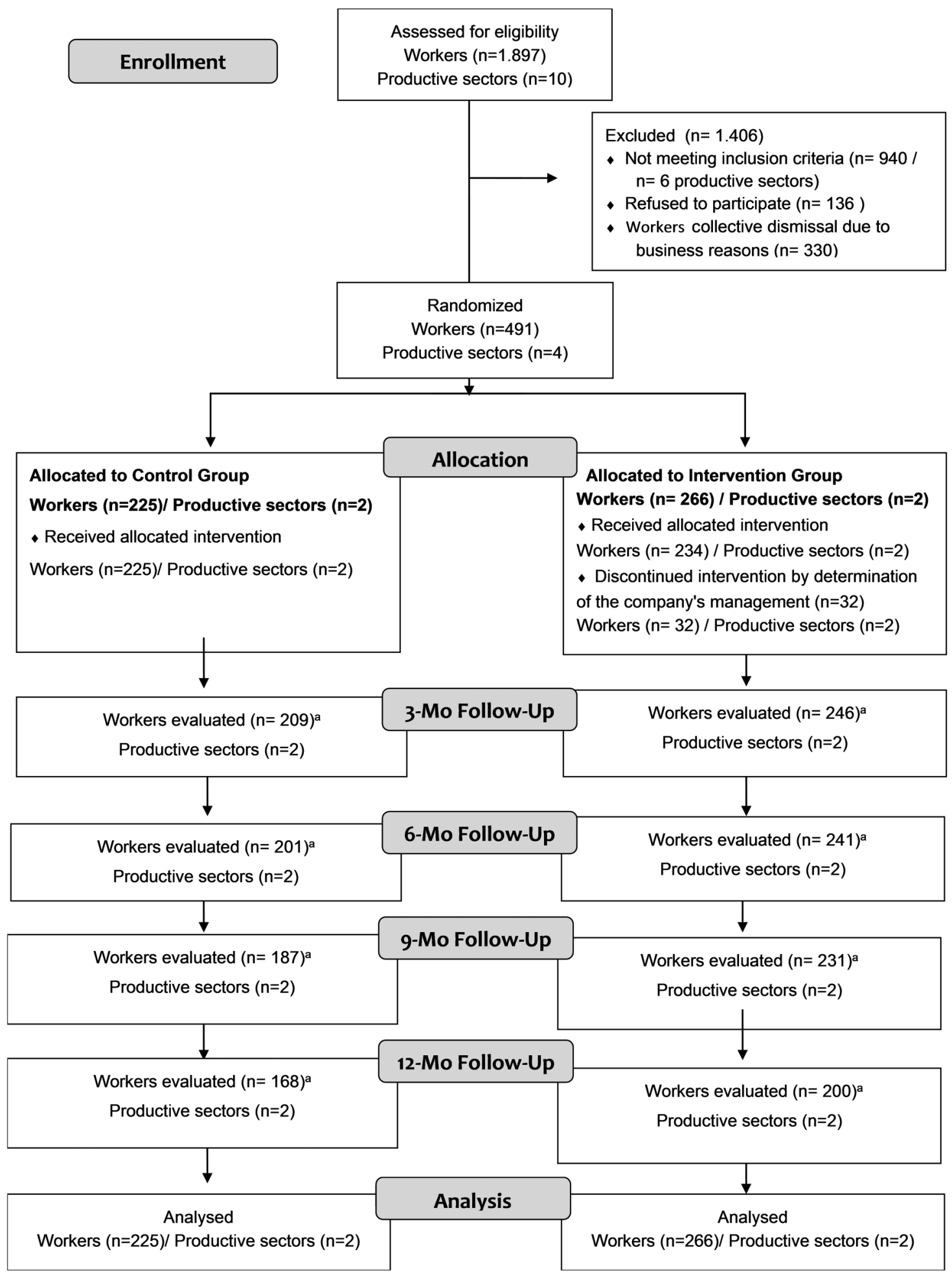

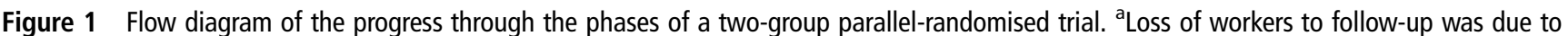
dismissal for business reasons. Mo, months. 
intervention group and $25.3 \%$ in the control group. Nevertheless, the total number of participants met the requirement of the sample size calculation, which required 116 workers per group, or 232 workers in total.

\section{Sociodemographic characteristics}

The participants were predominantly female $(77.8 \%)$ and had worked for the company a mean of 50 months. The sociodemographic variables of the two groups at baseline are given in table 1 .

Table 1 Sociodemographic variables of the two groups (job rotation and control) for all participants $(n=491)$

\begin{tabular}{lcc}
\hline Variable & $\begin{array}{c}\text { Intervention } \\
(\mathbf{n}=266)\end{array}$ & $\begin{array}{c}\text { Control } \\
(\mathbf{n}=225)\end{array}$ \\
\hline Sex & $72(21.1)$ & $30(13.3)$ \\
$\quad$ Male & $194(72.9)$ & $195(86.7)$ \\
Female & $28.4(7.8)$ & $32.5(9.0)$ \\
Age (years) & & \\
Marital status & $211(79.3)$ & $158(70.2)$ \\
Single & $49(18.4)$ & $60(26.7)$ \\
Married & $0(0.0)$ & $2(0.9)$ \\
Divorced & $3(1.1)$ & $3(1.3)$ \\
Widowed & $3(1.1)$ & $17(7.6)$ \\
$\quad$ Not mentioned & $12(4.5)$ & $67(29.8)$ \\
Education status & $58(21.8)$ & $130(57.8)$ \\
Illiterate & $183(68.8)$ & $8(3.6)$ \\
Elementary degree & $11(4.1)$ & $3(1.3)$ \\
High school & $2(0.8)$ & $56.9(44.3)$ \\
University & $49.6(43.2)$ & \\
Not mentioned & & \\
Length of employment & & \\
with company (months) & & \\
\hline Values aren (\%). & & \\
* Continuous variables are presented as & mean (SD). & \\
& & \\
\hline
\end{tabular}

Effect of JRP on the number of working hours lost due to sick leave for musculoskeletal disease

At the 12-month follow-up, both groups showed an increase in the number of working hours lost due to sick leave for musculoskeletal disease. The increase in hours lost was greater after 6 months of programme implementation. No significant differences between the groups were observed at any follow-up. For the within-group comparisons, the results demonstrated a significant difference for the 6-month, 9-month and 12-month follow-up within the intervention group. In addition, there was a significant difference for the 9-month and 12-month follow-up within the control group (table 2).

\section{Effect of intervention on musculoskeletal symptoms}

There was a significant reduction in symptoms only for wrists and hands $(p<0.05)$. Table 3 shows that the prevalence of musculoskeletal symptoms (pain, tingling, numbness) had decreased in almost all body regions (neck, shoulders, elbows, hands, upper back, lower back, hips, knees and feet) for both groups after 12 months.

\section{Effects of JRP on the perception of musculoskeletal pain risk factors, fatigue and psychosocial factors, and general health}

Table 4 shows the intervention effects on the four outcomes. Three of these are related to the effects of JRP on workers' selfperception of the occurrence of musculoskeletal pain, fatigue and psychosocial risk factors, and general health. The workers had a worse perception for all outcomes. No significant differences between groups were found for any outcome. In contrast, there was a significant difference for almost all outcomes in the within-group comparisons. The only exception was the perception of psychosocial factors and fatigue in the intervention group.

\section{Effects of JRP on productivity}

During the 12 months, there was a decrease in productivity, with a significant difference for both groups in the within-group

Table 2 Intervention effects (job rotation) on the number of working hours lost due to sick leave (mean and standard deviation) during 12-month follow-up of participants $(n=491)$. Results of the linear mixed-effects models (MIXED). [95\% Cl=95\% confidence interval.]

\begin{tabular}{|c|c|c|c|c|c|}
\hline & \multicolumn{2}{|c|}{$\begin{array}{l}\text { Primary outcome (working hours lost due to } \\
\text { sick leave per month)* }\end{array}$} & \multicolumn{2}{|c|}{$\begin{array}{l}\text { Unadjusted within-group mean differences } \\
\text { (baseline minus follow-up) }\end{array}$} & \multirow{2}{*}{$\begin{array}{l}\text { Adjusted between-group } \\
\text { mean differences } \\
\text { (intervention minus control) }\end{array}$} \\
\hline & Intervention $(n=266) \dagger$ & Control $(n=225) \dagger$ & Intervention $(n=266) \dagger$ & Control $(n=225) t$ & \\
\hline \multicolumn{6}{|c|}{ Intention-to-treat analysis } \\
\hline Baseline & $6.7(18.2)$ & $11.4(26.5)$ & & & \\
\hline 3 months & $9.0(19.1)$ & $11.3(20.8)$ & $2.3(-0.5$ to 5.0$)$ & $-0.1(-3.9$ to 3.8$)$ & $2.3(-44.2$ to 48.9$)$ \\
\hline 6 months & 83.7 (256.6) & $85.5(254.5)$ & $77.0 \ddagger(45.8$ to 108.1$)$ & $74.1 \ddagger(40.4$ to 108.0$)$ & $2.8(-43.7$ to 49.4$)$ \\
\hline 9 months & $105.3(284.2)$ & $123.0(305.1)$ & $98.6 \ddagger(64.2$ to 133.0$)$ & $111.6 \ddagger(71.1$ to 152.0$)$ & $-13.0(-59.5$ to 33.5$)$ \\
\hline 12 months & 143.9 (329.9) & 191.1 (368.6) & $137.1 \mp(97.2$ to 177.0$)$ & $179.8 \ddagger(131.1$ to 228.5$)$ & $-42.6(-89.2$ to 3.9$)$ \\
\hline \multicolumn{6}{|c|}{ Per-protocol analysis } \\
\hline Baseline & $6.4(19.2)$ & $12.1(28.9)$ & & & \\
\hline 3 months & $7.3(15.2)$ & $10.3(17.3)$ & $0.9(-2.0$ to 3.9$)$ & $-1.8(-6.2$ to 2.6$)$ & $-3.0(-6.3$ to 0.3$)$ \\
\hline 6 months & $10.8(29.6)$ & $13.7(23.7)$ & $4.4 \ddagger(0.4$ to 8.5$)$ & $-1.6(-3.2$ to 6.4$)$ & $-2.8(-8.5$ to 2.7$)$ \\
\hline 9 months & $15.7(37.8)$ & $16.5(33.0)$ & $9.3 \neq(4.1$ to 14.6$)$ & $4.4(-1.2$ to 10.0$)$ & $-0.76(-8.2$ to 6.6$)$ \\
\hline 12 months & $17.3(40.3)$ & $25.6(58.6)$ & $10.9 \neq(5.5$ to 16.3$)$ & $13.5 \ddagger(5.3$ to 21.7$)$ & $-8.3(-18.5$ to 1.9$)$ \\
\hline
\end{tabular}


Table 3 Intervention effects (job rotation) on the musculoskeletal symptoms during 12-month follow-up of participants ( $\mathrm{n}=491$ )

\begin{tabular}{|c|c|c|c|c|c|}
\hline \multirow[b]{3}{*}{ Region of musculoskeletal symptoms } & \multicolumn{4}{|l|}{ Frequency, $n(\%)$} & \multirow[b]{3}{*}{$\mathrm{p}$ Value } \\
\hline & \multicolumn{2}{|l|}{ Baseline } & \multicolumn{2}{|l|}{ 12-month follow-up } & \\
\hline & Intervention $(\mathrm{n}=\mathbf{2 6 6})$ & Control $(n=225)$ & Intervention $(n=266)$ & Control $(n=225)$ & \\
\hline Neck & $98(36.8)$ & $89(39.6)$ & $70(26.3)$ & 73 (32.4) & 0.29 \\
\hline Shoulders & $145(54.5)$ & $120(53.3)$ & $112(42.1)$ & $97(43.1)$ & 0.11 \\
\hline Upper back & $120(45.1)$ & $94(41.8)$ & 77 (28.9) & $83(36.9)$ & 0.85 \\
\hline Elbows & $18(6.8)$ & $18(8.0)$ & $12(4.5)$ & $23(10.2)$ & 0.12 \\
\hline Wrists/hands & $101(38.0)$ & $88(39.1)$ & $79(29.7)$ & $79(35.1)$ & $0.04 \dagger$ \\
\hline Lower back & $104(39.1)$ & $84(37.3)$ & $65(24.4)$ & $76(33.8)$ & 0.73 \\
\hline Hips/thighs & $30(11.3)$ & $36(16.0)$ & $22(8.3)$ & $28(12.4)$ & 0.65 \\
\hline Knees & $50(18.8)$ & $42(18.7)$ & $36(13.5)$ & $48(21.3)$ & 0.19 \\
\hline Ankles/feet & $75(28.2)$ & $55(24.4)$ & $43(16.2)$ & $58(25.8)$ & 0.52 \\
\hline
\end{tabular}

Results of McNemar's test.

${ }^{*}$ The number of participants assessed at the 12-month follow-up was 368 (200 in the intervention group and 168 in the control group).

†Significant difference within groups $(p<0.05)$. The intervention and control group showed improvement in symptoms after 12 months of intervention.

Table 4 Intervention effects (job rotation) on the secondary outcomes (mean and standard deviation) during 12-month follow-up of participants $(n=491)$. Results of the linear mixed-effects models (MIXED). [95\% Cl=95\% confidence interval.]

\begin{tabular}{|c|c|c|c|c|c|c|c|}
\hline \multirow[b]{3}{*}{ Secondary outcome } & \multicolumn{4}{|c|}{ Unadjusted group mean (SD) } & \multirow{2}{*}{\multicolumn{2}{|c|}{$\begin{array}{l}\text { Unadjusted within-group mean difference } \\
\text { (baseline minus follow-up) }\end{array}$}} & \multirow{3}{*}{$\begin{array}{l}\text { Adjusted between-group } \\
\text { mean difference } \\
\text { (intervention minus } \\
\text { control) }\end{array}$} \\
\hline & \multicolumn{2}{|l|}{ Baseline } & \multicolumn{2}{|c|}{ 12-month follow-up } & & & \\
\hline & $\begin{array}{l}\text { Intervention } \\
(n=266)\end{array}$ & $\begin{array}{l}\text { Control } \\
(n=225)\end{array}$ & $\begin{array}{l}\text { Intervention } \\
(\mathrm{n}=266)\end{array}$ & $\begin{array}{l}\text { Control } \\
(n=225)\end{array}$ & Intervention $(n=266)$ & Control $(n=225)$ & \\
\hline $\begin{array}{l}\text { Musculoskeletal pain risk } \\
\text { factors }(0-150)\end{array}$ & $72.5(37.9)$ & $77.9(36.3)$ & $84.1(33.1)$ & $85.6(33.9)$ & $11.9+(6.2$ to 17.6$)$ & $6.3+(1.0$ to 11.7$)$ & $4.6(-3.1$ to 12.2$)$ \\
\hline $\begin{array}{l}\text { Psychosocial factors and } \\
\text { fatigue }(0-100)\end{array}$ & $38.7(18.1)$ & $37.3(18.4)$ & $39.3(18.0)$ & $40.2(18.2)$ & $1.9(-0.6$ to 4.8$)$ & $2.7 \dagger(0.1$ to 5.3$)$ & $-1.5(-4.9$ to 2.0$)$ \\
\hline \multicolumn{8}{|l|}{ General health $(0-100)$} \\
\hline Physical domain & $64.2(15.5)$ & $62.3(15.5)$ & $58.0(13.6)$ & $58.2(14.3)$ & $-7.0 \dagger(-9.7$ to -4.2$)$ & $-4.3+(-6.9$ to -1.7$)$ & $-2.2(-5.8$ to 1.4$)$ \\
\hline Psychological domain & $68.7(15.5)$ & $67.8(15.2)$ & $64.5(12.3)$ & $63.5(12.5)$ & $-5.1 \dagger(-7.6$ to -2.6$)$ & $-4.5+(-6.8$ to -2.2$)$ & $-0.8(-3.4$ to 3.2$)$ \\
\hline Social domain & $68.4(18.8)$ & $66.0(20.0)$ & $61.7(15.6)$ & $60.9(14.9)$ & $-6.7 \dagger(-9.9$ to -3.4$)$ & $-5.6 \dagger(-8.9$ to -3.4$)$ & $-1.5(-5.9$ to 2.9$)$ \\
\hline Environmental domain & $50.2(13.7)$ & $46.3(15.2)$ & $46.1(10.4)$ & $42.2(13.4)$ & $-4.4 \dagger(-6.9$ to -1.9$)$ & $-3.8+(-6.3$ to -1.2$)$ & $-0.7(-3.5$ to 3.3$)$ \\
\hline Productivity (0-10) & $8.3(1.6)$ & $8.4(1.6)$ & $8.1(1.7)$ & $7.5(2.6)$ & $-0.4 \dagger(-0.1$ to -0.6$)$ & $-0.9+(-1.3$ to -0.6$)$ & $0.99(-0.85$ to 1.05$)$ \\
\hline
\end{tabular}

Results of linear mixed-effects models.

${ }^{*}$ The number of participants assessed at 12-month follow-up was 368 (200 intervention and 168 control).

comparisons. However, no significant differences were found between the groups (table 4).

\section{Blinding}

The evaluator blinding was confirmed by the percentage of agreement between the randomisation codes and the evaluator opinion on the intervention group $(58.3 \%)$ and the control group $(50.1 \%)(p>0.05)$.

\section{DISCUSSION}

According to a recent systematic review, this study is the first RCT to evaluate the effectiveness of job rotation for reducing working hours lost as a result of sick leave due to musculoskeletal diseases in industrial workers. ${ }^{8}$ The results show that job rotation was not effective for the intervention group compared with the control group. In fact, even more hours were lost during the 12 months of job rotation implementation. Job rotation was also not effective in reducing the prevalence of musculoskeletal symptoms, improving self-perception of musculoskeletal and psychosocial factors, or increasing productivity. Only the prevalence of musculoskeletal symptoms in wrists and hands showed a significant improvement after job rotation implementation.

There are several possible explanations for our findings. First, job rotation has never been a business strategy in these textile industries. For this reason, we believe that some workers were not able to adapt to this proposal, which generated new responsibilities, even with all the instructions before programme implementation about the benefits of job rotation that the workers would receive. In addition, the inclusion of tasks with high exposure level promoted changes in labour demand generated by job rotation schedules, which must have generated the feeling that musculoskeletal overload would increase, especially for workers who had lighter work. In addition, a lot of collective dismissals for business reasons have occurred in this industry, which may have influenced workers negatively. As psychosocial factors are important determinants of the success of job rotation, all these issues may have contributed to the reasons why job rotation was not more effective, compared with the control group, especially in reducing the number of hours lost due to sick leave for musculoskeletal disease. $^{34}$ 
The prevalence of musculoskeletal symptoms in the wrists and hands was the only outcome for which job rotation showed significant improvement. These findings agree with those of Roquelaure $e t a l^{35}$ and Klussmann et al. ${ }^{36}$ Roquelaure et al evaluated the association between occupational factors and carpal tunnel syndrome (CTS). They concluded that workers who did not perform job rotation had a higher chance of developing CTS. Klussmann et al evaluated the prevalence of musculoskeletal symptoms in the upper extremities and the symptompredicting factors at visual display terminal workstations. The results showed that the prevalence of hand/wrist symptoms was influenced by the frequency of job rotation. In our study, this result may be related to the fact that the wrists and hands were exposed for less time because of greater variation in lifting, gripping and repetitive tasks. In other body regions, such as neck, shoulders and lower back, muscular contractions may have remained static, independently of job rotation.

It is important to note that, for our study, job rotation was planned specifically to prevent and control musculoskeletal diseases. $^{12} 37$ We evaluated the job characteristics, production methods, and biomechanical and psychosocial factors, and classified exposure levels for all tasks. We created the schedule on the basis of criteria and parameters recommended by the scientific literature. All workers were trained so as to be $100 \%$ fit for each task. It should also be mentioned that the JRP deployment process has been widely accepted, management was involved, and the JRP was agreed to by managers and most workers during the 12 months specified in the study design. Perhaps, the positive results of the implementation can be attributed to the ergonomics programme which the company has sponsored for 10 years. This programme includes workstation design, participatory ergonomics, guidelines, adjustments and rest breaks at work. On the other hand, despite these precautions, some tasks still had a high risk of exposure, which may have affected our study by not demonstrating the effectiveness of the JRP with respect to hours lost because of musculoskeletal disease. Although we believe we have carefully taken into account all theoretical aspects for implementation of job rotation, we are aware that we need to report on the difficulties of the theory/practice of integration in our study, since most published studies on job rotation do not detail how they were implemented and what tools were used to assess the risk, to ensure reproducibility of the study.

Two recent systematic reviews ${ }^{8} 9$ have already demonstrated important findings that support job rotation ineffectiveness. The evidence in each study was weak because of the methodological quality, which varied between fair and poor, and non-RCT designs. Most studies have used cross-sectional designs. ${ }^{8}$ Maybe for this reason, the studies found conflicting (positive and negative) results for job rotation effects on musculoskeletal disorders. $^{8} 9$ For example, Guimarães et $a l^{12}$ showed a significant reduction in the occurrence of musculoskeletal injuries, absenteeism, turnover, rework and spoilage for workers who had performed job rotation for 3.5 years. On the other hand, Fredriksson et $a l^{38}$ found that physical workload and the frequency of musculoskeletal disorders increased significantly in the group of workers who performed job rotation schedules in a line system. Similar results were found by Balogh et $a l^{39}$ and de Oliveira Sato and Coury. ${ }^{19}$

Our study had several methodological strengths: cluster RCT study design and its statistical power; recruitment of a large population, as well as the inclusion of workers involved in diverse tasks with different workloads; randomisation by production sector, which minimises possible contamination between workers from the intervention and control groups; use of standardised questionnaires to measure study outcomes; and blinding of the assessor. As a result, our study findings can be generalised to work settings with characteristics similar to those of this study (ie, manufacturing industries with production layouts organised into lines or cells, with a rhythm that is not determined by machines, and which allow switching between tasks with different biomechanical demands and levels of risk for musculoskeletal pain and disorders).

In fact, on the basis of the results of this study, it can be concluded that there is no advantage in using the JRP to decrease working hours lost due to musculoskeletal symptoms or disease or to prevent and control musculoskeletal disorders. These results challenge the concept that job rotation is a good organisational strategy for preventing and controlling musculoskeletal disorders, particularly in work settings in which exposure levels cannot be reduced because of the characteristics of the job or through physical measures. ${ }^{4}$ However, translating these results to all manufacturing industries requires care, with a need to consider the specifics of the job, settings, and organisation preferences and necessities. In practice, it is up to managers and occupational health professionals who provide occupational health services in different companies to decide about the use of job rotation. At the end of this study, we informed the textile industry of our results; although no evidence emerged of job rotation effectiveness, the managers decided to continue with job rotation, even after being informed of the results. They understand that the results of this intervention were positive in many aspects, including development of workers with multitasking skills, reduction of monotony and boredom, and good acceptance of labour inspection organs.

We recommend future studies be conducted in other companies, especially in industries that already have a culture of job rotation established. Descriptive studies that report on potential strategies for companies to implement job rotation are equally relevant and should be pursued, even before new RCTs. We defend this premise because we have learnt a great deal from this study and have confronted job rotation theory within the challenges of implementing this intervention. Companies see job rotation as an organisational strategy of production and are concerned about overexposure of workers. The results of this study compel us to reflect on earlier findings showing that allocation of workers to tasks at different levels of exposure may increase, rather than reduce, exposure to risk factors. In this way, it is necessary to attain a broad knowledge of the risks involved in the tasks, and, to do this, we must assess the analytical tools we have for occupational exposure. It is also important to improve the accuracy of methods for assessing physical and mental exposure of workers, in order to allow more accurate identification of exposure variation, for the creation of job rotation schedules. Practical implications of this study reveal the need for careful implementation of a JRP in industrial settings.

\section{Limitation}

A limitation of this study resulted from changes in the trial design that were beyond our control. Managers did not allow follow-up for secondary outcomes every 3 months, as described in the research project, because of the time that would be spent by workers in answering the questionnaires. Therefore, data for secondary outcomes were collected only at baseline and after the 12-month intervention. Managers also did not allow two of the tasks included in the intervention group $(n=32$ employees) to continue in the study, as the workers boycotted the rotation, causing a negative effect on productivity. However, all statistical analysis was conducted on an intention-to-treat basis. This 
ensures that non-compliance, protocol deviations, withdrawal, and anything that happens after randomisation may influence the results, resulting in an overoptimistic estimate of the efficacy of an intervention. ${ }^{40}$

Another limitation was the considerable loss to follow-up rates on secondary outcomes found after 12 months. Unfortunately, loss to follow-up is a common problem in prevention studies, ${ }^{41}$ particularly in industrial settings where determinations of organisations may affect the conduction of a study. ${ }^{10}$ However, our loss to follow-up rates was $<30 \%$, which did not affect our ability to draw firm conclusions. ${ }^{42}$ Besides, the total number of participants exceeded the number of participants defined by sample-size calculation.

In the original proposal published in the clinical trial registration and study protocols, it was indicated that the costeffectiveness of interventions would be calculated according to the cost-effectiveness incremental. During the study, however, it was not possible to have access to all related direct or indirect costs of the proposed intervention.

\section{CONCLUSION}

After 12 months, the results of this large cluster RCT showed that job rotation was not effective in reducing the number of working hours lost due to sick leave for musculoskeletal disease.

Contributors All authors contributed to all stages of the study.

Funding This study was supported by the National Counsel of Technological and Scientific Development (CNPq), Brazil (473651/2013-0), who had no involvement in any step of the trial.

Competing interests None declared.

Patient consent Obtained.

Ethics approval Research ethics committee of Universidade Cidade de São Paulo.

Provenance and peer review Not commissioned; externally peer reviewed.

\section{REFERENCES}

1 Asensio-Cuesta S, Diego-Mas JA, Cremades-Oliver LV, et al. A method to design job rotation schedules to prevent work-related musculoskeletal disorders in repetitive work. Int J Prod Res 2012;50:7467-78.

2 Jorgensen $M$, Davis K, Kotowski S, et al. Characteristics of job rotation in the Midwest US manufacturing sector. Ergonomics 2005;48:1721-33.

3 Cristini A, Pozzoli D. Workplace practices and firm performance in manufacturing Int J Manpower 2010;31:818-42.

4 Leider PC, Boschman JS, Frings-Dresen MH, et al. When is job rotation perceived useful and easy to use to prevent work-related musculoskeletal complaints? App/ Ergon 2015;51:205-10.

5 Azisi N, Zolfaghari S, Liang M. Modeling job rotation in manufacturing systems: the study of employee's boredom and skill variations. Int J Prod Econ 2010;123:69-85.

6 Rissen D, Melin B, Sandsjo L, et al. Psychophysiological stress reactions, trapezius muscle activity and neck and shoulder pain among female cashiers before and after introduction of job rotation. Work Stress 2002;16:127-37.

7 Costa AM, Miralles C. Job rotation in assembly lines employing disabled workers. Int J Prod Econ 2009;120:625-32.

8 Padula RS, Comper MLC, Sparer EH, et al. Job rotation designed to prevent musculoskeletal disorders and control risk in manufacturing industries: a systematic review. App/ Ergon 2017;58:386-97.

9 Leider PC, Boschman JS, Frings-Dresen MH, et al. Effects of job rotation on musculoskeletal complaints and related work exposures: a systematic literature review. Ergonomics 2015;58:18-32.

10 Schelvis RM, Oude Hengel KM, Burdorf A, et al. Evaluation of occupational health interventions using a randomized controlled trial: challenges and alternative research designs. Scand J Work Environ Health 2015;41:491-503.

11 Diego-Mas JA, Asensio-Cuesta S, Sanchez-Romero MA, et al. A multi-criteria genetic algorithm for the generation of job rotation schedules. Int J Ind Ergon 2009;39:23-33.

12 Guimarães LB, Anzanello MJ, Renner JS. A learning curve-based method to implement multifunctional work teams in the Brazilian footwear sector. Applied ergonomics 2012;43:541-7.
13 Comper MLC, Padula RS. The effectiveness of job rotation to prevent work-related musculoskeletal disorders: protocol of a cluster randomized clinical trial. BMC Musculoskelet Disord 2014;15:170.

14 Mahmud N, Kenny DT, Md Zein R, et al. Ergonomic training reduces musculoskeletal disorders among office workers: results from the 6-month follow-up. Malays J Med Sci 2011;18:16-26.

15 Robson LS, Stephenson CM, Schulte PA, et al. A systematic review of the effectiveness of occupational health and safety training. Scand J Work Environ Health 2012;38:193-208.

16 Comper ML, Costa LO, Padula RS. Clinimetric properties of the Brazilian-Portuguese version of the Quick Exposure Check (QEC). Rev Bras Fisioter 2012;16:487-94.

17 Comper MLC, Costa LOP, Padula RS. Quick Exposure Check (QEC): a cross-cultural adaptation into Brazilian-Portuguese. Work 2012;41(Suppl):2056-9.

18 Lamarão AM, Costa LC, Comper ML, et al. Translation, cross-cultural adaptation to Brazilian- Portuguese and reliability analysis of the instrument Rapid Entire Body Assessment-REBA. Braz J Phys Ther 2014;18:211-17.

19 de Oliveira Sato T, Coury HJ. Evaluation of musculoskeletal health outcomes in the context of job rotation and multifunctional jobs. App/ Ergon 2009;40:707-12.

20 Filus $\mathrm{R}$, Okimoto ML. 0 efeito do tempo de rodízios entre postos de trabalho nos indicadores de fadiga muscular-o ácido lático. $14^{\circ}$ Congresso Brasileiro de Ergonomia; Curitiba- PR; 2006.

21 WHO. World Health Organization. International classification of diseases and related health problems-tenth revision (ICD 10). Geneva: World Health Organization, 2010.

22 Linaker $C$, Harris EC, Cooper $C$, et al. The burden of sickness absence from musculoskeletal causes in Great Britain. Occup Med (Lond) 2011;61:458-64.

23 Valirad F, Ghaffari M, Abdi A, et al. Interaction of physical exposures and occupational factors on sickness absence in automotive industry workers. Glob J Health Sci 2015;7:44458.

24 Barros EN, Alexandre NM. Cross-cultural adaptation of the Nordic musculoskeletal questionnaire. Int Nurs Rev 2003;50:101-8.

25 Coluci M, Alexandre N, Rosecrance J. Reliability and validity of an ergonomics-related Job Factors Questionnaire. Int J Ind Ergon 2009:39:995-1001.

26 Comper MLC, Padula RS. Ergonomic risk assessment in textile industry workers by two instruments: quick exposure check and job factors questionnaire. Fisioter Pesq 2013;20:215-21.

27 Moriguchi CS, Alem MER, Veldhoven MV, et al. Cultural adaptation and psychometric properties of Brazilian Need for Recovery Scale. Rev Saude Publica 2010;44:131-9.

28 Sluiter JK, de Croon EM, Meijman TF, et al. Need for recovery from work related fatigue and its role in the development and prediction of subjective health complaints. Occup Environ Med 2003;60(Suppl 1):i62-70.

29 Fleck MP, Louzada S, Xavier M, et al. Aplicação da versão em português do instrumento abreviado de avaliação da qualidade de vida "WHOQOL-bref". Rev Saude Publica 2000:34:178-83.

30 Pedroso B, Pilatti LA, Gutierrez GL, et al. Calculation of scores and descriptive statistics of WHOQOL-bref through Microsoft Excel. Rev Bras Qual Vida 2010;2:31-6

31 Kessler RC, Barber C, Beck A, et al. The World Health Organization Health and Work Performance Questionnaire (HPQ). J Occup Environ Med 2003;45:156-74

32 de Oliveira RF, Liebano RE, Costa Lda C, et al. Immediate effects of region-specific and non-region-specific spinal manipulative therapy in patients with chronic low back pain: a randomized controlled trial. Phys Ther 2013;93:748-56.

33 Twisk JW. Longitudinal data analysis. A comparison between generalized estimating equations and random coefficient analysis. Eur J Epidemiol 2004;19:769-76.

34 Ellis T. Implementing task rotation. Occup Health Saf 1999;68:82-4.

35 Roquelaure $Y$, Mechali S, Dano C, et al. Occupational and personal risk factors for carpal tunnel syndrome in industrial workers. Scand I Work Environ Health 1997;23:364-9.

36 Klussmann A, Gebhardt $H$, Liebers $F$, et al. Musculoskeletal symptoms of the upper extremities and the neck: a cross-sectional study on prevalence and symptom-predicting factors at visual display terminal (VDT) workstations. BMC Musculoskelet Disord 2008;9:96.

37 Tharmmaphornphilas W, Norman BA. A methodology to create robust job rotation schedules. Ann Operations Res. 2007:155:339-60.

38 Fredriksson K, Bildt C, Hagg G, et al. The impact on musculoskeletal disorders of changing physical and psychosocial work environment conditions in the automobile industry. Int JInd Ergon 2001;28:31-45.

39 Balogh I, Ohlsson K, Hansson GA, et al. Increasing the degree of automation in a production system: consequences for the physical workload. Int J Ind Ergon 2006:36:353-65.

40 Gupta SK. Intention-to-treat concept: a review. Perspect Clin Res 2011;2:109-12.

41 Galea S, Tracy M. Participation rates in epidemiologic studies. Ann Epidemiol 2007:17:643-53.

42 Higgins J, Green S. Cochrane handbook for systematic reviews of interventions version 5.0.1 The Cochrane Collaboration 2008. The Cochrane Collaboration, 2008. 